\title{
Literature Survey on Solar Based Refrigerator
}

\author{
Tejas Narkhede ${ }^{1}$, Bhangale Nikhil Haribhau ${ }^{2}$ \\ ${ }^{1,2}$ UG students Dr D Y Patil Institute of Engineering, Management And Research Akurdi Pune
}

Received on: 16 July, 2021

Revised on: 15 August, 2021

Published on: 17 August, 2021

\begin{abstract}
Solar energy is one of the most feasible solution to replace conventional cooling systems to produce refrigeration. To decrease Ozone depletion and greenhouse emission, Much more research activities commenced for the development of refrigeration. In this paper, different types of refrigeration methods such as Solar Electric Refrigeration System, Solar Absorption System and Solar Mechanical Refrigeration System have been reviewed. The methods of refrigeration depend upon Reversed Carnot cycle, which gives an idea about adiabatic compression and expansion. As the trend is changing there is problem of consumption of electricity so, to minimize this we can prefer renewable sources of energy like solar energy which is efficient and rich source of energy. Also world is experiencing that in present refrigerator which generates cooling effect by refrigerants such as Freons, HCF'S, CFC'S etc. But, main limitation is that it causes global ozone depletion. Now, this problem can be prevailed by Peltier effect and by protecting the environment. Refrigeration is an old concept from industrial point of view. But, with reference to academics a lot of research is required to visualize about various aspects like coefficient of performance etc. Condenser, Evaporator, Compressor, Expansion valve are the main components of refrigeration system.[5] Several refrigerants are used in refrigeration according to their characterstics and properties.
\end{abstract}

Keywords- Vapour Compression cycle, Solar Electric Refrigeration System, Solar Absorption System, Solar Mechanical Refrigeration System Condenser, Evaporator, Compressor, Expansion valve, Peltier effect etc.

\section{I - INTRODUCTION}

$\mathrm{R}$ body so its temperature is lowered and maintained at a level below the temperature of surroundings. A solar based refrigerator is a type of refrigerator which works on electricity directly provided by solar energy. The heat taken out from the refrigerated space is rejected to atmosphere which looks like a natural receiver of heat. The common use of refrigeration is the preservation of articles, especially for perishable food stuff for short and long duration of time and also used in off-grid location. In modern era, refrigeration have many wide applications.[6] Energy in the form of heat is eliminated from low temperature reservoir and relocated to high temperature reservoir. The work is done by mechanical means but it can be performed by magnetism and laser.

Refrigeration is used for drying purposes and recreational designs. Working fluids are used for carrying away heat are known as 'Refrigerants'. By cooling at a temperature above freezing, it is good to gain storage time for safe marketing. Nowadays, there has been steady development of refrigeration. So, this paper gives review about the development of a solar based compressor free mini refrigerator. This refrigerator will be useful for cooling purposes for small objects and will have a relatively small chilling time as compared to the normal refrigeration systems. Also, for the backup, this refrigerator will be attached to a dynamo-based charging system which will maintain the smooth operation of refrigerator in case of non-availability of solar power. Solar energy is not source of air pollution 


\section{International Journal of Innovations in Engineering and Science, www.ijies.net}

and influences on surface of Earth. It is a continuous source which can remain infinite period.

Solar power is also required to put the vaccines at the relevant temperature to avoid deterioration. Plug in refrigerators with proper backup of generators are used in well prospered countries. But, in case of developing countries, there can be shortage of electricity supply so various types of refrigeration technologies are preferred. Solar refrigerators are instigated in developing nations to drop the used of kerosene and gas-powered absorption refrigerated coolers which became one of the best alternative source of energy. Utilization of kerosene have been soared off because it catches fire quickly and problems of maintaining accurate temperatures. Refrigeration was successfully used for making artificial ice. At present condition, refrigeration have become household purposes. Refrigeration means extraction of heat from a substance at low temperature level and transfers to the system at high temperature level. In such a case body is known as refrigeration system.

\section{II - LITERATURE REVIEW}

Ice Harvesting:- The first scientist to discover solar based refrigerator was “ Otto Mohr' in 1935. From many years, ice is used for preservation and refrigeration. Through a decades ago, harvesting of snow and ice was a continuos work for ancient people: Romans, Greeks etc. The discovery of chemical refrigeration was one of the first step near to the artificial refrigeration. During $20^{\text {th }}$ century, America became first nation who started technology of harvesting of ice. Frederic Tudor, who is known as ' Ice King' worked for creating best insulation for large distance shifting of ice. In the view of thermal engineering approach, refrigeration technology plays a vital role in the industrial applications.[5]

In 1756 , the method of artificial refrigeration was firstly experimented by William Cullen in Scotland in Glasgow university. For producing vacuum over container of diethyl Ether, Cullen used pump, which is heated at a high temperature absorbing heat from surrounding air. This experiment generated ice, but had no use in practical applications.

Benjamin Franklin and John Hardly, Professor from Cambridge University demonstrated an experiment to find the principle of evaporation for rapid cooling of an object. They introduced that evaporation of highly volatile liquids could be used to lower down temperature of an object past freezing point of water. They both conducted an experiment with bulb of mercury thermometer and lowered the the temperature of thermometer to $7^{0} \mathrm{~F}$ and that time ambient temp was $65^{\circ}$ F. Franklin examined that soon after they passed to the freezing point of water $32{ }^{0} \mathrm{~F}$. On the surface of bulb of thermometer, thin film of ice is formed.[6]

In 1954, Kirpichev and Baum reported that a solar refrigerator capable of producing of $250 \mathrm{~kg}$ of ice per day which was operated by vapour compression principle.

In 1961, Chinnappa investigated intermittent solar refrigeration system theoretical with absorption cycle for ammonia-water and ammonia-lithium nitrate combinations and compared results experimentally.

In 1981, Flechon et al build a refrigerator working on vapour absorption cycle with electric energy to simulate the performance. In February 2011, Mehmet Azmi Aktacir demonstrated, "Experimental study of a multipurpose PV-refrigerator system.” [1]

Solar energy transmits energy in the form of solar radiation to produce electricity, may be it is photovoltaic. In active solar techniques, solar panels and solar collectors are used to mix the energy.[10]

\section{III- REFRIGERATION SYSTEMS}

A) Solar Electric Refrigeration System:-

B) Solar Thermal Refrigeration System:-

C) Solar Mechanical Refrigeration System:-

(A) Solar Electric Refrigeration System:-

\section{Construction of Solar Electric Refrigeration System:-}
a) Solar Panel
b) Charge Controller cum Converter
c) Battery
d) Load
e) Auxiliary Energy Sources

a) Solar Panel:-

Photovoltaic (PV) module widely known as Solar panel are mounted on roof so that they will get maximum exposure to sun light. The Photons or particles of light when fall on PV panel the light energy get converted into electric energy by photovoltaic effect. The solar panel has an input capacity of $16 \mathrm{~V}$ and output capacity is $21 \mathrm{~V}$. The minimal refrigerator holds about three to four solar 


\section{International Journal of Innovations in Engineering and Science, www.ijies.net}

panels. It converts sunlight into DC electricity which is useful for various purposes.

b) Charge Controller cum Converter: -

Charge controller is type of voltage/current regulator to put the batteries safe from overcharging. It is a simple, precise and efficient controller. In case if we are running AC appliances in that case Charge controller cum converter converts DC current into AC.

c) Battery:-

Battery is used to convert chemical energy into electrical energy. It is used to store solar energy. In off grid PV system, batteries are needed to provide power during time of low or no sunlight areas.

d) Load: -

Load refers to power used by devices that are included in a system. They are appliances in electric system that are joined to solar PV system like T.V, Radio, Refrigerators and Computers. In our case Refrigerator.[3]

e) Auxillary Energy Sources:-

Auxillary energy sources are the sources which are used as supplement for the system. During cloudy days when PV panels don't get enough sunlight to run the system and charge battery this auxiliary supply is used to run system. (Fig 1)

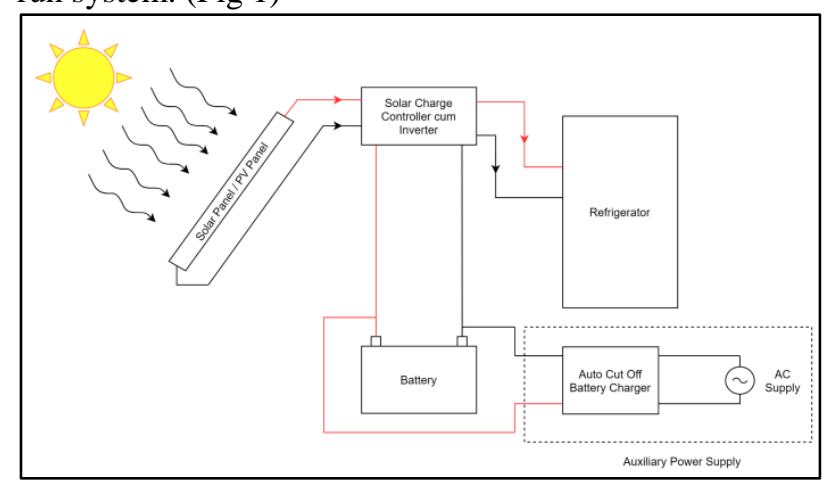

Fig 1 - Solar Electric Refrigeration System

\section{Working of Solar Electric Refrigeration System:-}

1. In this type of refrigeration system Solar energy get converted into electric energy which will later get used to run the system.

2. PV cell is composed of semiconducting material such as Polycrystalline silicon etc. When PV cell get exposed to sunlight photons which are also known as particles of light, light energy of these is get converted into electrical energy. This effect is known as photovoltaic effect.[3]

3. This electric energy is in the for of DC current. This energy flows through wire up to Charge Controller/ Charge Controller cum Converter.

4. Part of this energy is get stored into battery, while other part is used to run the system. This part is done by Charge controller which regulates the charge in order to protect battery.

5. If appliance is running on DC supply, then Charge controller transfer this energy to the appliance. IF appliance is running on $\mathrm{AC}$ supply, then Charge Controller cum Converter is used which convert $\mathrm{DC}$ into $\mathrm{AC}$ and then that $\mathrm{AC}$ current is used to run appliance.

6. In cloudy days when PV panel don't get exposed to enough sunlight energy stored in battery will get used to run system.

7. In certain cases, if main system or energy source is not capable of running Refrigeration unit then Auxiliary Power supply is used to run Refrigerator.

\section{B) Solar Absorption Refrigeration System:-}

\section{Construction of Solar Thermal Refrigeration System:-}

a) Solar Collector: - The basic function of solar collector is to collect more rays from sun and converted into heat energy. This Solar collector have pipes through which fluid keep circulating. As fluid flows through pipes heat energy absorbed by Solar Collector is transferred to fluid flowing resulting increase in temperature of fluid.

b) Generator: - The purpose of generator is to collect heat energy from solar collector through pipes and boil aqua ammonia solution to convert into vapour form. Fluid which is get heated using solar collector is circulated through so that heat of fluid gets transferred to Aqua-Ammonia solution.

c) Condenser: - The main feature of condenser is to change phase of vapour refrigerant and convert the vapour into liquid.

d) Evaporator:- The basic function of evaporator is to provide hear transfer area through which heat is absorbed by vapour refrigerant from cold chamber. 


\section{International Journal of Innovations in Engineering and Science, www.ijies.net}

e) Pump:- The Pump is used to help in circulation of weak and strong solution.

f) Expansion Valve:- It is used to meter the amount of refrigerant to be supplied to the evaporator and to reduce pressure upto evaporator pressure. (Fig 2)

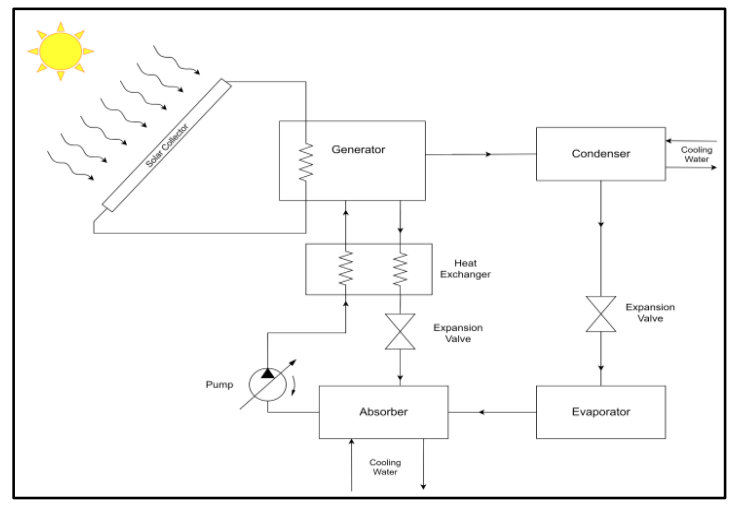

Fig 2 - Solar Thermal Refrigeration System

Working of Solar Thermal Refrigeration System:-

1. In the Solar Thermal Refrigeration System, solar energy is used to reduce the usuage of electricity. The merit of this system is it can use more amount of sunlight than PV module.

2. Solar Thermal Refrigeration System consists of four parts-solar collector, thermal refrigeration unit, Heat Exchanger and Evaporator.

3. Solar collector is selected on the basis of temperature required for refrigeration system. This solar collector is mounted on roof where when it comes to exposure of sunlight it absorbs the heat from sunlight and transfer that to fluid flowing through it. This results in increase in temperature of fluid.

4. Then this heated fluid is passed through the generator so that it transfers heat to the refrigerant around it. During this it don't get mixed with the refrigerant as it flows through coil.

5. Once refrigerant get heated, vapour of refrigerant enters in condenser where it gets cooled and phase change takes place means vapour get converted into liquid refrigerant.

6. This liquid refrigerant flows through expansion valve and later enters to evaporator. In evaporator it absorbs heat and then Ammonia enters absorber. Where low pressure ammonia vapour is absorbed by water thus forming Aqua-Ammonia solution.

7. This solution is pumped to heat exchanger where it gets heated before entering generator.

8. In generator this solution is heated hence high-pressure ammonia vapour enters the condenser and weak aqua-ammonia solution send back to absorber. While going back to absorber remaining heat of this weak aquaammonia solution is transfer to rich solution via heat exchanger.[3]

9. By Energy Savings Trust, cost of solar thermal refrigeration system is between $\$ 4000$ to $\$ 5000$. It comprises of all installation parts.

10. Solar Thermal System is more reliable than Solar Electric Refrigeration System.(Fig 2)

\section{C) Solar Mechanical Refrigeration System: - Construction of Solar Mechanical System:}

a) Solar Collector:- Solar collector is the device which absorbs solar heat energy and transfer it to liquid flowing through pipes. This heats up the liquid.

b) Heat Exchanger:- Heat exchanger exchanges heat between two fluids. Here it is used to transfer heat of fluid which gets heated in the solar collector to the working fluid of Rankine cycle.

c) Turbine:- It is one of the most vital part of the Rankine cycle where vapour of working fluid of Rankine cycle enters and thus turbine produces mechanical work in the form of shaft work.

d) Condenser: -It is used in Rankine cycle as well as Vapour Compression cycle. It converts vapour into liquid i.e phase change process takes place.

e) Pump:-Increase pressure of liquid coming out of condenser and pumps up the liquid to heat exchanger. This component is used in Rankine cycle.

f) Compressor:- It is part of Vapour Compression cycle. It increases the pressure of vapour refrigerant and it is compressed isentropically.

g) Expansion valve:- This device controls the flow of fluid and reduces pressure of it and regulates evapaorator's temperature to accurate value. 


\section{International Journal of Innovations in Engineering and Science, www.ijies.net}

h) Evaporator:- Evaporator provides surface area through which heat is absorbed by refrigerant from surrounding medium.

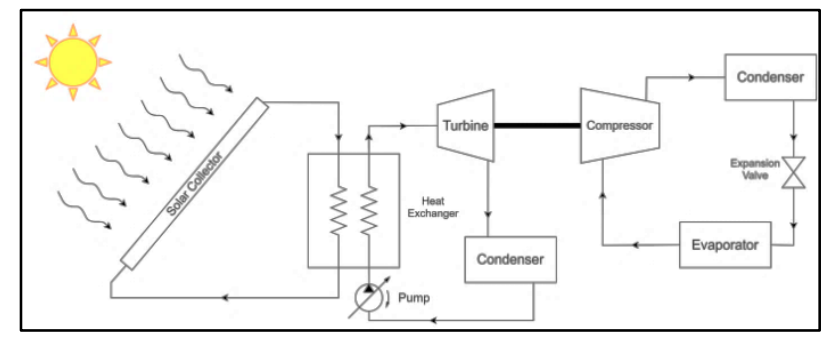

Fig 3 - Solar Mechanical Refrigeration System

\section{Working:-}

1. Solar Mechanical Refrigeration works on vapour compression cycle which is operated by mechanical power that is produced by solar heat power cycle (Rankine cycle).

2. In this type of cycle, fluid is converted into vapour form at particular pressure with the help of heat exchanger with a heated fluid by solar collectors.

3. Flow of vapour takes place from turbine for developing mechanical power. The fluid coming from expansion valve is condensed and pushed back where it is vaporized again.

4. With increase in temperature of vapour form fluid, Rankine cycle efficiency increases passing through expansion valve. Moreover, total efficiency of solar collector starts decreasing with increase in the distributed energy.

5. In Rankine cycle working fluid gets heated in heat exchanger. This liquid gets converted into vapour which is sent to turbine. Energy of this vapour converted into shaft work.[2]

6. Remaining vapour is conveyed to condenser where it is converted into liquid. This liquid gets pumped to heat exchanger again thus completing cycle.

7. Shaft power of turbine is used to run compressor which compresses the vapour refrigerant which is passed to condenser. Whereas, vapour refrigerant gets converted into liquid which is trasmitted to evaporator via expansion valve.

8. Evaporator absorbs heat thereby creating cooling effect after which liquid refrigerant gets converted into vapour which is reverted back to compressor thus by concluding the circuit.
9. This system is very crucial, when solar trackers are used which is costly and complex in structure. The efficiency of this system is lower than that of solar electric refrigeration system. (Fig 3)

\section{Applications:-}

1. Preservation of foods, fruits, vegetables, serums and medicines etc.

2. Small scale industries.

3. Manufacturing of ice slurries.

4. Cooling of cement concrete on construction sites and liquids in chemical process plants.

5. Liquefaction of gases.

6. Cooling of beverages and cold-drinks.

\section{Advantages: -}

1. High reliability and Precise temperature control and occupies less space.

2. Eco friendly and noise less operation.

3. Low cost and high effectiveness.

4. Design is very simple.

\section{Disadvantages:-}

1. COP is less as compared to conventional refrigeration system.

2. In rainy season it cannot be possible to charge battery from solar energy and it depends on weather conditions.

3. Production of power is not uniform throughout a day and intensity of sun also changes sometimes.

4. Main limitation is that solar panels are hazardous for house roofs.

\section{IV- RESULT \& DISCUSSION}

After going through all the Solar Refrigeration System and analyzing them properly we found that these systems are very coherent and effective. But as this can only work properly in certain scenario i.e. shiny atmosphere. This system doesn't give satisfactory results when conditions are occurred like rain or unclear clouds. This problem can be resolved if we can find a good energy storing device. In case of Solar Electric Refrigeration System, we have such device in the form of Battery. Also, for this system we can not rely completely on Solar based system as it is dependent on 


\section{International Journal of Innovations in Engineering and Science, www.ijies.net}

environmental conditions hence, we need some auxillary power supply or system to achieve desired refrigeration effect.

\section{V- CONCLUSION}

Nowadays, Solar Power plays vital role in encountering the energy requirements. It is being expanded at a very rapid rate and its enormous applications in many areas are being inspected. The refrigerator provides an efficient and economical solution to the areas where there is no electricity and cooling is required. The main objective of this seminar was to develop a mini solar refrigerator. Solar refrigeration is very useful term in the future. Solar technologies are mentioned in this paper. Rankine cycle is useful for high cooling capacities. An entrancing option for future need is that to integrate many eminent refrigeration cooling cycles and methods. Numerous researchers are testifying to develop solar refrigeration systems with low initial cost and high efficiency.

\section{REFERENCES}

[1] Mehmet Azmi Aktacir, "Experimental Study of multipurpose PV refrigerator system" International Journal of Physical Sciences Vol. 6(4), pp. 746-757, 18 February, 2011, ISSN 1992-1950, 15 February,2011.

[2] Sanford A. Klein , Douglas T. Reindl, "Solar Refrigeration" American Society of Heating, Refrigerating and Air-Conditioning Engineers, ASHRAE Journal (Vol. 47, No.9, September 2005).

[3] Abhishek Sinha and S.R. Karale, "A Review on Solar Powered Refrigeration" International Journal of Engineering Research \& Technology ISSN 2278-0181 ( Vol. 2 Issue 2, February-2013).

[4] Todd Otanicar, "Robert A. Taylor, Patrick E. Phelan, " Prospects of Solar Coolong - An Economic and Environmental Assessment" Solar Energy 86 (2012)1287-1299, 17 February 2012.

[5] M.M.. Hussain, I. Dincer and S.M.Zubair, " A feasibility study of using thermal storage of energy in conventional air conditioning system" International Journal of Energy Research, 2004; 28:955-967.

[6] Poonam Dhankar, "A Study on Refrigeration" International Journal of Science and Research, ISSN 2319-7064, ( Vol. 3 Issue 5 , May 2014).

[7] Pankaj Kumar Yadav, "Design of Compressor less solar powered refrigeration" International Journal of Scientific Research and Management (IJSRM), (Vol.4, Pages 4480-4485, 2016).

[8] Maneewam,Tipsaenpromand, "Thermal comfort study of a compact Thermoelectric Air Conditioner" International Journal of Electronic Materials May 2012.
[9] Arjun Kumar GB, S. Sushma, L.Priyanka, S. Vijay, G.A. Thouqhir Pasha, " Design and Implementation of Peltier Based Solar Powered Air Conditioning and Water Heating System" International Conference on Recent Trendsin Electronics Information and Communication Technology (RTEICT), 2018.

[10] Ayman Jamal Alazazmeh and Esmail M Mokheimer, “ Review of Solar Cooling Technolgies" Journal of Applied Mechanical Engineering" ISSN 2168-9873, 2015. 